\section{Alegato pedagógico en Talca}

Pedagogical plea in Talca

Carmen Espegel

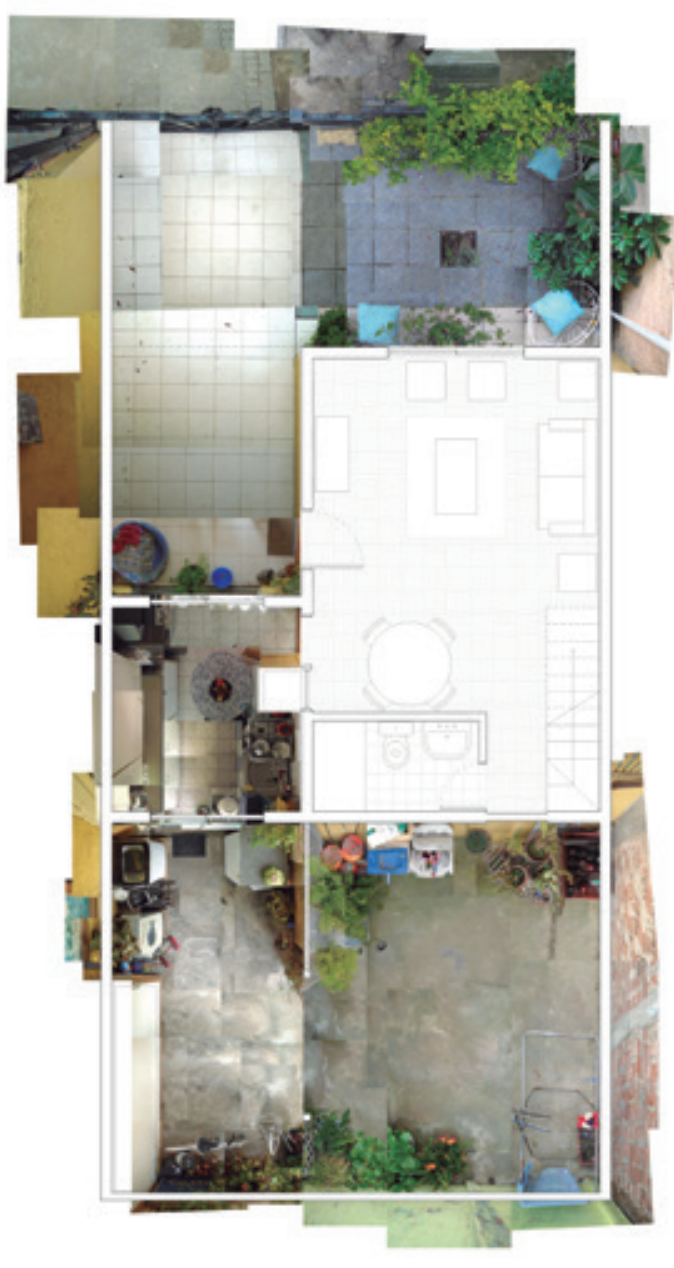

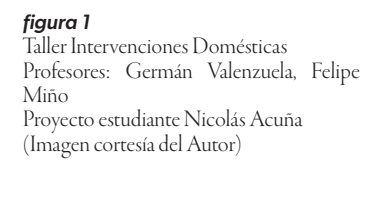

Palabras Clave

Talca

Arquitectura
Habitar

Habitar

Doméstico
Learning by doing
ABSTRACT The article is an argument about the particular wa
of teaching Projects in the Schod of Architecture at the University Talca (Chile), where the territory, the
material and the social are united i a thought and a constructive action
carried out by the students in the own houses in order to reformulate living in a critical way. Key Words Domestic, Learning by doing

Resumen El artículo es un alegato sobre la particular forma de enseñanza de Proyectos en la Escuela de Arquitectura en la Universidad de Talca (Chile), donde el territorio, lo material y lo social se unen en un pensamiento y una acción constructiva realizada por los alumnos en sus propias casas con el objeto de reformular el habitar de un modo crítico.

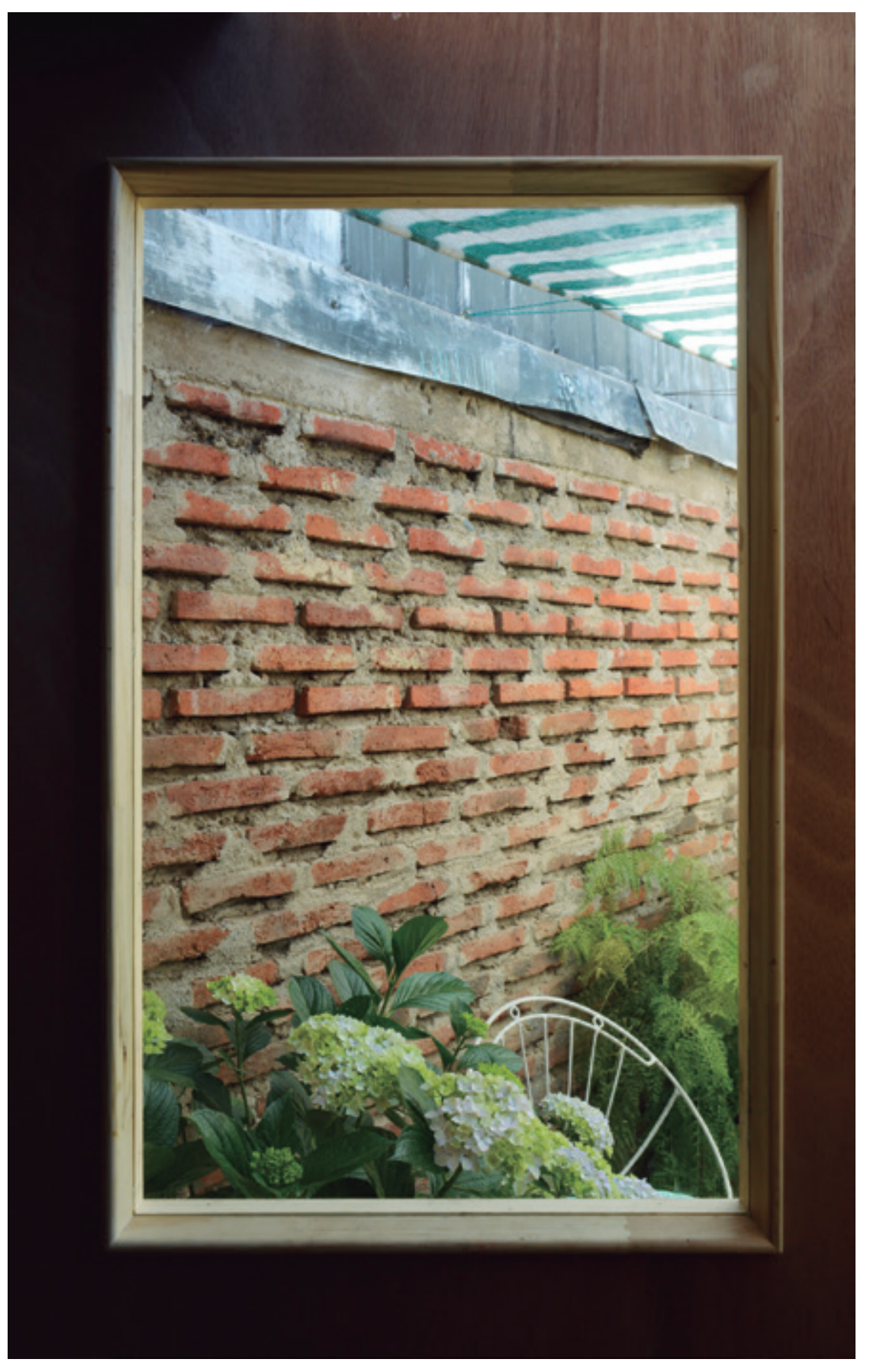



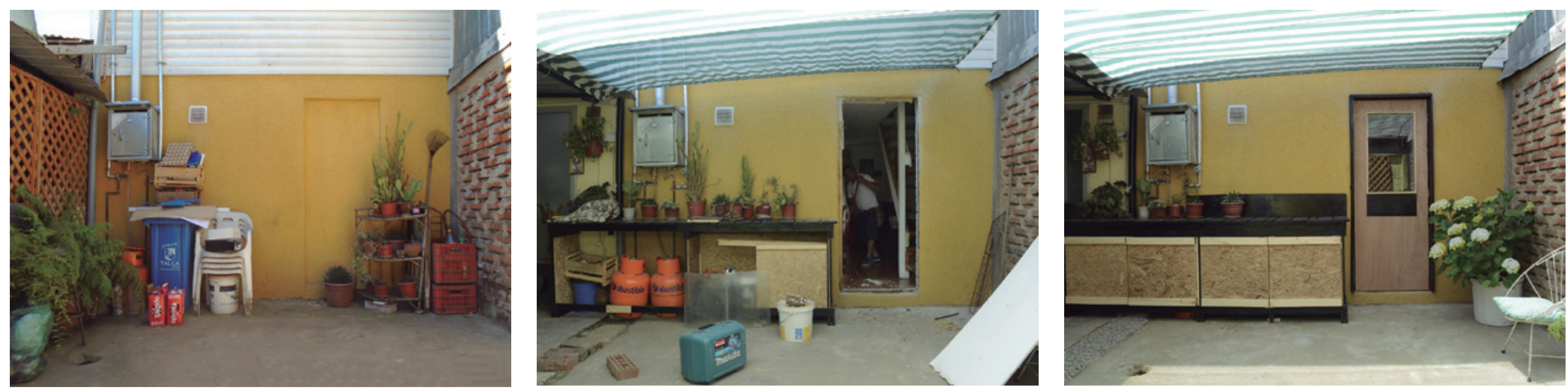

figuras 3,4 y 5

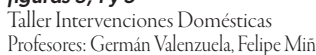

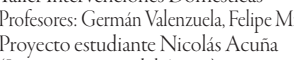

Proyecto estudiante Nicolis
(Imagen cortesiá del Autor

Parece razonable detenernos y pensar sobre la capacidad real de la arquitectura para resolver problemas que se comprometen con las personas. Una arquitectura menos festiva, más centrada en la conducta cotidiana, en lo que todos sentimos y en como ésta, haciendo mejores los lugares y construyendo atmósferas más intensas, perfecciona y transforma el medio. Y haciéndolo, sería deseable que nos transformarse también a nosotros.

La arquitectura es áspera como la vida, pero también es hermosa cuando plantea un compromiso ético, social y, sin duda, intelectual. Esa es la arquitectura que alguna vez hemos olvidado y que sin duda merece la pena revisar. Esa es la arquitectura que se enseña en Talca desde 1999, en una universidad periférica, en un país periférico y en un continente periférico, por utilizar las palabras del profesor Germán Valenzuela.

Esta escuela propone que el pensamiento y la acción proyectual son la misma cosa. Coinciden con la idea clásica de que poético es "lo hecho que hace, lo construido que construye". Consideran que es una ocasión de debate, de razonamiento continuo, algo más complejo y denso en su formación intelectual y cultural que la mera resolución atinada o sagaz de un problema.
Las intervenciones domésticas realizadas en los propio hogares de los estudiantes durante el periodo de la pandemia resultan una formulación profunda sobre pues aúna lo antropológico con lo cultural, la teorí y la práctica, el futuro y el pasado, lo conceptual y lo pragmático.

Han hecho suya la teoría pedagógica de John Dewey resumida en aprender haciendo, con la particularidad de que su fuerte enraizamiento con el contexto les hace prácticamente únicos en la enseñanza de la arquitectura pues la observación del entorno físico, económico, material y humano, produce unas respuestas beneficiosas también para la propia comunidad.

El planteamiento global que subyace en la metodología propuesta en Talca es demostrar que cuando concurren determinadas relaciones de coherencia especulativa entre lo territorial, lo material y lo social, se alcanzan lo más altos niveles de expresión arquitectónica. En todo caso, los estudiantes son iniciados por medio de una afinada observación del entorno a través del análisis de las relaciones entre programa y forma, flujos y espacio, técnica y construcción o cultura y comunidad, para as poder desarrollar sus proyectos con la complejidad que la operación requiere. La validez educativa está enmarcada por una evaluación constante de cada relación frente a cuales serán capaces de ofrecer legitimidad a la operativa de diseño.

Resulta difícil reflexionar sobre el habitar pues está relacionado con lo habitual, con el hábito, con el morar, la morada como lugar de la costumbre, la vida diaria, la cotidianeidad, pero también de los infinitos prejuicios que conlleva la rutina. Ahora bien, ellos han entendido el hábito a modo de cualidad ya que incluye un alcance etnográfico y moral sobre el conocimiento de las personas que ejecutan algo con frecuencia. Ese conocer propio de las habilidades con la que los seres humanos habitan sería una especie de "inteligencia inconsciente" citando a Félix Ravaisson, que establece un arquetipo colectivo del habitar, donde el ser humano logra su identidad personal. En esa secuencia espaciotemporal fenomenológica de gestos, palabras y objetos, se estructuraría la escala ritual o mítica del refugio. Pero, además, la pandemia ha ayudado sobremanera, porque ha estresado y tensado de tal manera sus hogares que ha provocado una velocidad extrema a la hora de analizar desde otra perspectiva los potenciales de la misma.

En Talca, lo ordinario, en la definición de Enrique Walker, sería el denominador común de una serie de nociones que tienen relación con la apropiación e instrumentalización de las denominadas condiciones existentes: lo banal, lo cotidiano, lo hallado, lo popular, y se transformaría en la materia prima del proyecto. En Talca, los alumnos acompañados por sus profesores han sido capaces de descubrir lo que les rodea, interrogándose sobre la habilidad de transformar la intrascendencia en oportunidad. Las situaciones de conflicto, de actitud y conciencia social, y la voluntad para extrañar y extrañarse se convierten en técnicas de diseño arquitectónico que ayudan a desprejuiciarse y arrancar, sin perder la capacidad crítica. Y así, este remoto lugar de Chile, con su manera de entender lo local ha llegado a conectarse con el mundo global. 

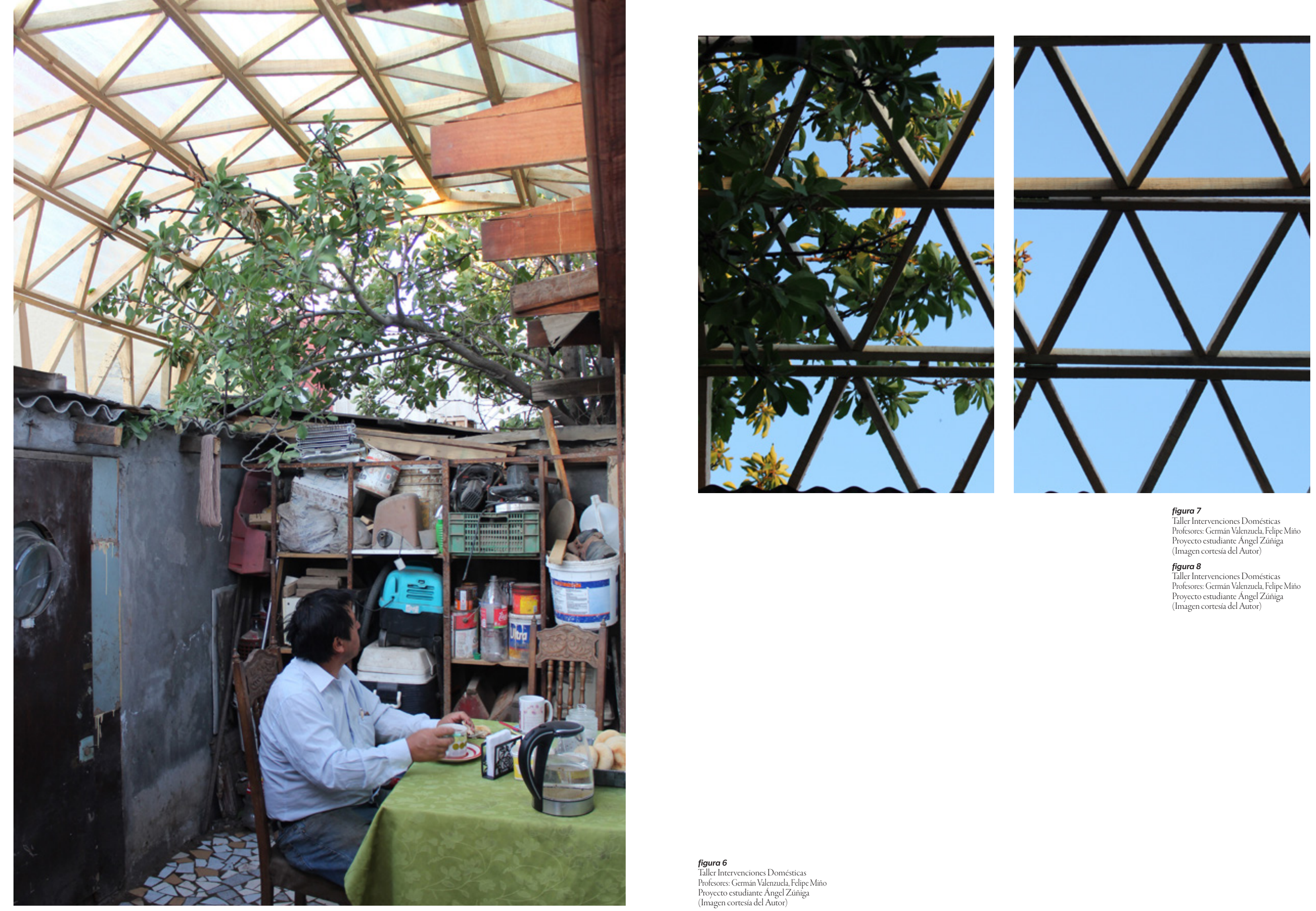

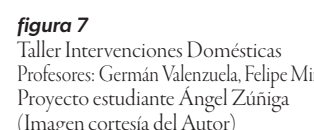

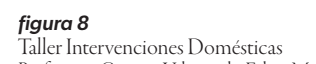

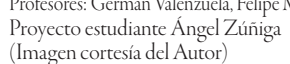

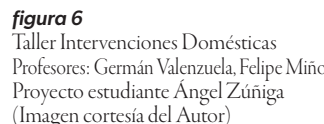


